\title{
ENVIRONMENTAL MONITORING AND CONTROLLING SYSTEM FOR MUSHROOM FARM WITH ONLINE INTERFACE
}

\author{
Arjuna Marzuki and Soh Yan Ying \\ School of Electrical and Electronic Engineering, Universiti Sains Malaysia, Penang, \\ Malaysia
}

\begin{abstract}
Agriculture sensors play an important role in modern agriculture. The use of sensors in various agriculture sectors minimizes the environmental impact on crops, helps in increasing yield and saving cost of operation. Among all agriculture industries in Malaysia, the mushroom industry is a comparatively new and small. As most of the mushroom farms in Malaysia are small-scaled, their production capability is limited by inadequate environmental control system and the lack of financial resources to upgrade the systems. This paper presents an environmental monitoring and controlling system to monitor and control the environmental conditions in a mushroom farm. It enables user to monitor temperature, humidity, carbon dioxide concentration and light intensity in a mushroom farm on an android device by using ThingSpeak online platform. The control algorithm is able to control devices in a mushroom farm automatically based on feedback from the sensors to maintain the environment in an optimum condition for mushroom growth. The measured percentage error of temperature, humidity, carbon dioxide and the light using the developed system was as low as $0.4 \%, 1.5 \%, 2.2 \%$ and $1.34 \%$ respectively.
\end{abstract}

\section{KEYWORDS}

Agriculture, Interface Circuit, Internet of Things, Monitoring and Control, Sensor, Wireless.

\section{INTRODUCTION}

The contribution of agriculture to the Malaysia's national GDP (gross domestic product) has declined from nearly $50 \%$ in the 1950 s to $9.7 \%$ in year $2008[1,2]$. The decline is due to several challenges. Some of the major challenges faced by agriculture sector in Malaysia are persistent poverty among rural farming community, food insecurity, labour intensive and high cost of land [3].

Among all agriculture products in Malaysia, mushroom is found to be a viable option to develop more reliable sources of income, especially for small-scale farmers [4]. In fact, mushrooms are listed as one of the seven high-valued crops by Malaysian government [5]. Besides generating income, it can also improve food security by increasing diversity. This is because mushrooms have short growing time, requires limited land and low investment as the growing medium is widely available [4].

Mushroom industry is comparatively new in Malaysia compared to other agricultural industry [6]. The productivity of domestic production of mushrooms is low and is unable to meet the demand of the market. Thus, Malaysia has to import tons of mushrooms every year since 2009. The import has reached more than 10 million tons in 2012, driven by high local demand [6]. Besides, mushroom farming is very labor-intensive [7]. Thus, to expand the industry in Malaysia, an automatic system is needed to increase the yield of mushrooms with less labor.

DOI:10.5121/ijcsit.2017.9402 
Currently, a timer-controlled misting system is used to control the humidity in most of the smallscale mushroom farms in Malaysia. This method is not accurate as humidity in the air varies according to the weather. A timer-controlled system may cause excess moisture, which encourages certain contaminates.

Mushrooms are a type of fungus and they do not contain chlorophyll [8]. Generally, the conditions can be summarized into temperature, humidity, light and fresh air [9]. Air flow of the mushroom growing room is an important aspect of mushroom growing as it directly affects the carbon dioxide content of the room [10].

Growth cycle of mushrooms can be simplified into two stages - the vegetative phase, which consists of mycelia expansion and maturation, and the reproductive phase [11]. To cultivate mushrooms, a mycelium culture is allowed to propagate on sterilized cereal grains, forming spawn. The spawn is inoculated into a sterilised substrate and the substrate is allowed to incubate. During incubation, mycelium grows throughout the substrate and uses up the nutrients in it. This process is called spawn run [12]. During spawn run, the optimum temperature is around 25 degrees Celsius and high carbon dioxide concentration is favorable. After that, the mycelium reaches the reproductive stage and is capable of producing mushrooms. Key factors which induces the production of mushrooms are sudden decrease in temperature (decrease of 5 to 10 degrees Celsius), and sudden decrease in carbon dioxide concentration [8]. After that, the optimum temperature for growth is around 10 to 25 degrees Celsius, $85 \%$ to $92 \% \mathrm{RH}$ (relative humidity), carbon dioxide concentration less than $600 \mathrm{ppm}$ (parts per million) and 500 lux to 2,000 lux for 12 hours [9]. As different phases require different humidity, temperature, carbon dioxide and carbon dioxide concentration, a system with pre-set conditions for different phases could make it easier for mushroom farmers.

Mushroom farming is labor-intensive and requires precision. Without suitable environmental condition, mushrooms could hardly reproduce. Timer-controlled humidifier used by most of the mushroom farmers in Malaysia is not consistent in maintaining the humidity and temperature in the mushroom farms, causing lower productivity. Thus, sensor-based environment control system is needed.

Most of the mushroom farmers in Malaysia are small-scaled farmers with just a few workers or none at all which do not operate 24 hours. Most of the time no one is at the mushroom farm. Thus, a remote monitoring system is needed to monitor the condition of the mushroom farm to prevent undesired conditions that might cause the death of mushrooms.

In order to overcome the problems stated above, a system that can monitor and control the environmental condition remotely is required. The objectives of this work are to design an interface circuit for agricultural sensors such as light sensor, carbon dioxide sensor and temperature and humidity sensor, and to design a remote monitoring system which includes a user interface to display correct data from the sensors and a close-loop control system to maintain optimum growth environment for mushrooms by controlling temperature, humidity, carbon dioxide concentration and light intensity.

\section{RELATED WORK}

There are a number of proposed systems in the past few years. One of them is a temperature and humidity monitoring system using AT89S52 as the controller, SHT10 as temperature and humidity sensor and TC35i GSM (Global System for Mobile communication) Module for wireless communication. The system is able to detect temperature and humidity and display via a Nokia 3310 LCD (liquid crystal display) module. When temperature or humidity exceeds the 
limit, the system will send short messages to mobile phones to alert the user [13]. Another system is a greenhouse monitoring and control system based on GSM. This system is more complicated compared to the previous system, as it does not only allow data acquisition, it also allows user to control humidity, temperature and soil moisture via SMS (Short Message Service). The temperature sensor used is LM35DZ and the humidity sensor used is HIH-4000-001 [14]. Some effort in the design and implementations of an indoor environmental monitoring system based on Arduino microcontroller had also been made. The system consists of a wireless module, a main module and dialer module. The dialer module will make a call when there is fire and send an SMS if two or more reading are out of acceptable range for more than 10 seconds. It also allows user to set four phone numbers which the dialer will call or send sms to by sending a SMS to the dialer [15]. A more recent system is a ZigBee-based energy efficient environmental monitoring alerting and controlling system. The system consists of an ARM7 processor, various sensors and ZigBee module. Sensors gather various physical data such as temperature, humidity and soil moisture from the field and transmit it to the processor and to the end user via ZigBee communication [16].

All these mentioned works do not allow monitoring and controlling via a graphical user interface. In addition, low cost implementation of Internet of Things for control and monitoring in mushroom agriculture sector could hardly be found. Also, many of the systems available in the market is not designed especially for mushroom cultivation but for general environment monitoring and control.

\section{MethodologY}

Figure 1 shows the flow chart of this work. Firstly, the system functionality was designed. Then, the interface circuits were designed and built one by one. The first interface circuit designed was the interface circuit of temperature and humidity sensor, followed by the interface circuit of lightdependent resistor and interface circuit of $\mathrm{CO} 2$ (carbon dioxide) sensor. Next, the source code was drafted. Then, the circuits were combined and tested to see if it fulfills the requirement. The troubleshooting process was repeated until the system worked well and fulfilled its requirements. Lastly, testing was done and results were evaluated.

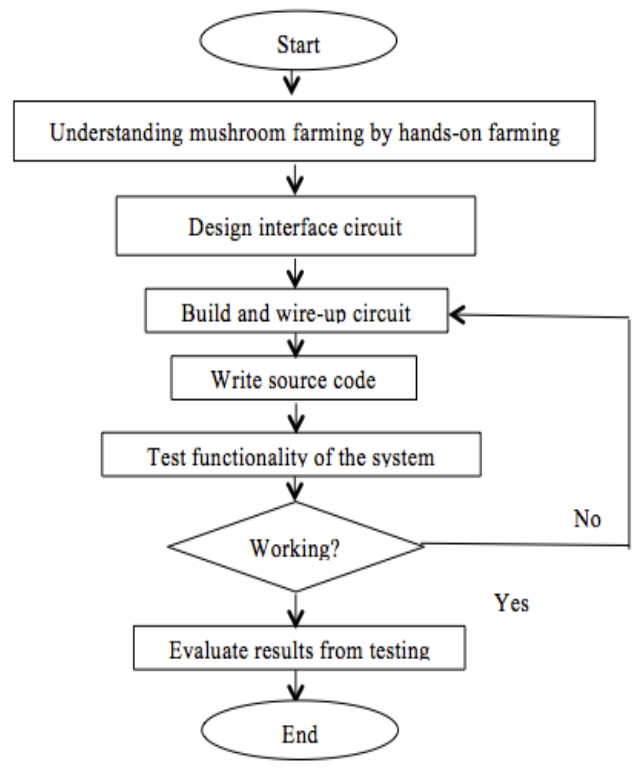

Figure 1. Flow chart of the project 


\subsection{System Overview}

The system consists of two main parts: the monitoring system and the control system. The monitoring part starts with data acquisition from the temperature and humidity sensor, carbon dioxide sensor and LDR (light-dependent resistor) using Arduino Uno. The data is then sent to the Cloud. The graphs of temperature, humidity, carbon dioxide concentration and light intensity can be viewed using ThingSpeak. ThingSpeak is an online interface for IoT (Internet of Things) projects. The control system includes processing data acquired from the sensors and controls appliances such and humidifier, fan and light to regulate the environment inside the mushroom farm according to the mode of environment selected. There are three modes of environment: spawn-run, pin head initiation and cropping. Different modes have different set of required environmental conditions as shown in Table 1 [9].

Table 1. Environmental conditions in different operating modes.

\begin{tabular}{|c|c|c|c|}
\hline & Spawn-run mode & Pin head initiation mode & $\begin{array}{c}\text { Cropping } \\
\text { mode }\end{array}$ \\
\hline Humidity & $90 \% \mathrm{RH}$ & $95 \% \mathrm{RH}$ & $85 \% \mathrm{RH}$ \\
\hline Temperature & $25{ }^{\circ} \mathrm{C}$ & $19{ }^{\circ} \mathrm{C}$ & 20 to $25^{\circ} \mathrm{C}$ \\
\hline Carbon dioxide & $20,000 \mathrm{ppm}$ & $600 \mathrm{ppm}$ & Less than $600 \mathrm{ppm}$ \\
\hline Light & Off & 2,000 lux for 12 hours & Above 500 lux for 12 hours \\
\hline
\end{tabular}

\subsection{Hardware Implementation}

The schematic diagram of the interface circuit is shown in Figure 2. The circuit consists of temperature and humidity sensor DHT22, gas sensor MQ135, LDR, WiFi module ESP8266-01, solid state relay G3MB, and AC (alternating current) control device, push button switch, Arduino UNO microcontroller, switch, LEDs (light - emitting diode) and various resistors.

In Figure 2, the power socket was represented by the AC power supply symbol. Live wire was connected to the G3MB relay, while neutral wire was connected to the AC device. G3MB relay, DHT22, MQ135, LDR, switch and LEDs were connected to the $5 \mathrm{~V}$ dc power supply from Arduino Uno, while ESP8266-01 were connected to $3.3 \mathrm{~V}$ dc power supply of Arduino Uno. The switch was for user to switch among 3 modes of the system: pin-head initiation mode, spawn run mode and cropping mode, and the LEDs were to indicate the current active mode.

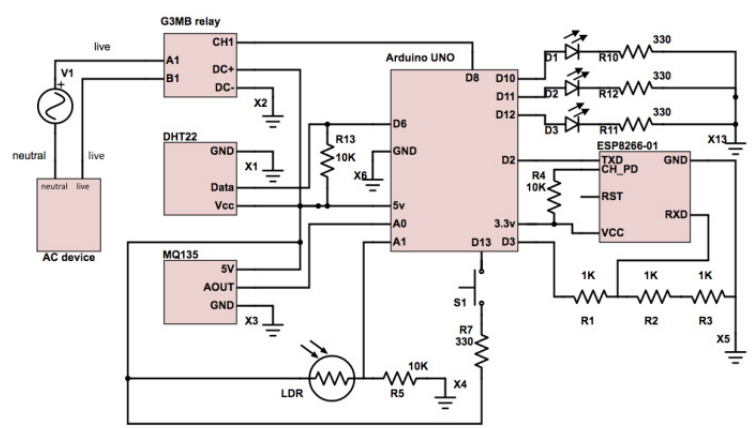

Figure 2. Schematic diagram of the interface circuit 


\subsection{Software Implementation}

The overall program flow is shown in Figure 3. The program starts with data acquisition from the temperature and humidity sensor, carbon dioxide sensor and LDR. Next, the control algorithm enables the control system to take appropriate actions based on the data acquired to control and maintain the environmental condition in the mushroom farm at the desired condition. Then, the system transmits the data from the sensors to a cloud for remote monitoring. The whole program is developed using Arduino IDE.

Data acquired from the sensors was monitored via ThingSpeak online interface. The first step was to sign up for a free account. Then, a new channel was created. In this project, four fields in the channel were used to record temperature, humidity, carbon dioxide concentration and light intensity. The channel was set to private and API keys were used to write data to the channel or read data from the channel. Data from the sensors was written to this ThingSpeak channel via ESP8266 WiFi module. Data stored in ThingSpeak cloud can be accessed anytime via WiFi connection.

The data can also be downloaded in CSV (Comma- Separated Values) format for storage and further analysis. Figure 4 shows the sample of CSV file downloaded from ThingSpeak.

An Android app interface was designed using Virtuino to display data from ThingSpeak channel 247738 for ease of monitoring, as mobile phone is more portable compared to a personal computer. As the ThingSpeak channel was set to private, the read API key had to be used to read data from the channel. Figure 5 shows the android app interface.

Besides displaying the values of sensors, the app was also designed to alert the user when any of the sensor values goes beyond the threshold. Alarm in the mobile phone will be triggered by the app and notification will be shown in the mobile phone when the relative humidity drops below $85 \% \mathrm{RH}$, when temperature rises above 25 degrees Celsius, or when carbon dioxide concentration rises above $600 \mathrm{ppm}$. Figure 6 shows the notification when a threshold is crossed. 
International Journal of Computer Science \& Information Technology (IJCSIT) Vol 9, No 4, August 2017

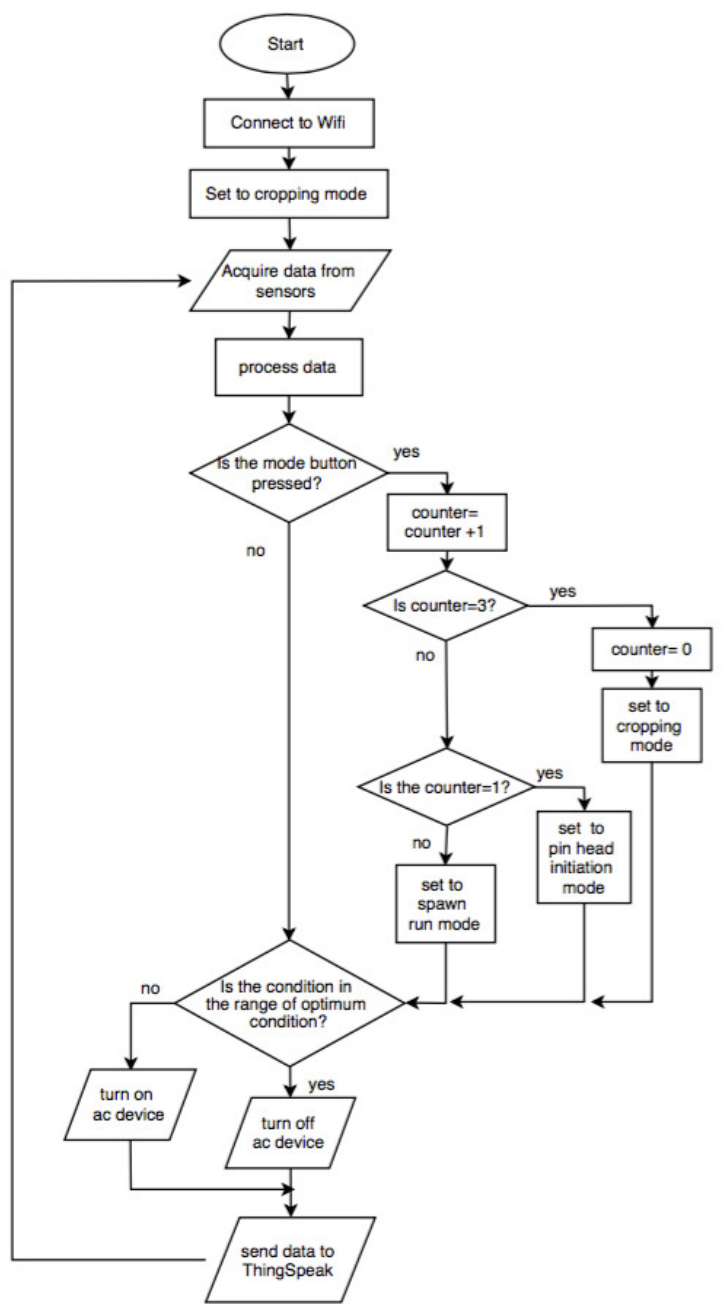

Figure 3. Main program flowchart

\begin{tabular}{|c|c|c|c|c|c|c|}
\hline 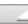 & A & B & C & D & E & $\mathbf{F}$ \\
\hline 1 & created_at & entry_id & field1 & field2 & field 3 & field 4 \\
\hline 2 & 2017-03-04 13:40:21 UTC & 1 & 26.2 & 48.6 & 399 & 500 \\
\hline 3 & 2017-03-04 13:40:43 UTC & 2 & 26.1 & 48 & 402 & 510 \\
\hline 4 & 2017-03-04 13:41:05 UTC & 3 & 26 & 48.3 & 405 & 498 \\
\hline 5 & 2017-03-04 13:41:27 UTC & 4 & 26 & 47.6 & 400 & 495 \\
\hline 6 & 2017-03-04 13:41:49 UTC & 5 & 25.9 & 47.5 & 398 & 500 \\
\hline 7 & 2017-03-04 13:42:11 UTC & 6 & 25.8 & 47.4 & 400 & 507 \\
\hline 8 & 2017-03-04 13:42:33 UTC & 7 & 25.8 & 47.3 & 400 & 509 \\
\hline 9 & 2017-03-04 13:42:55 UTC & 8 & 25.7 & 47.5 & 402 & 514 \\
\hline 10 & 2017-03-04 13:43:17 UTC & 9 & 25.7 & 47 & 399 & 501 \\
\hline 11 & 2017-03-04 13:43:38 UTC & 10 & 25.7 & 47.3 & 400 & 620 \\
\hline 12 & 2017-03-04 13:44:00 UTC & 11 & 25.7 & 46.9 & 410 & 616 \\
\hline 13 & 2017-03-04 13:44:22 UTC & 12 & 25.6 & 46.7 & 415 & 625 \\
\hline 14 & 2017-03-04 13:44:44 UTC & 13 & 25.6 & 46.2 & 417 & 602 \\
\hline 15 & 2017-03-04 13:45:06 UTC & 14 & 25.6 & 46.3 & 410 & 507 \\
\hline 16 & 2017-03-04 13:45:28 UTC & 15 & 25.6 & 46 & 408 & 509 \\
\hline 17 & 2017-03-04 13:45:50 UTC & 16 & 25.5 & 45.6 & 399 & 514 \\
\hline 18 & 2017-03-04 13:46:12 UTC & 17 & 25.5 & 44.7 & 402 & 500 \\
\hline 19 & 2017-03-04 13:46:54 UTC & 18 & 25.5 & 46.2 & 405 & 510 \\
\hline 20 & 2017-03-04 13:47:16 UTC & 19 & 25.5 & 45.2 & 400 & 498 \\
\hline
\end{tabular}

Figure 4. CSV file downloaded from ThingSpeak 


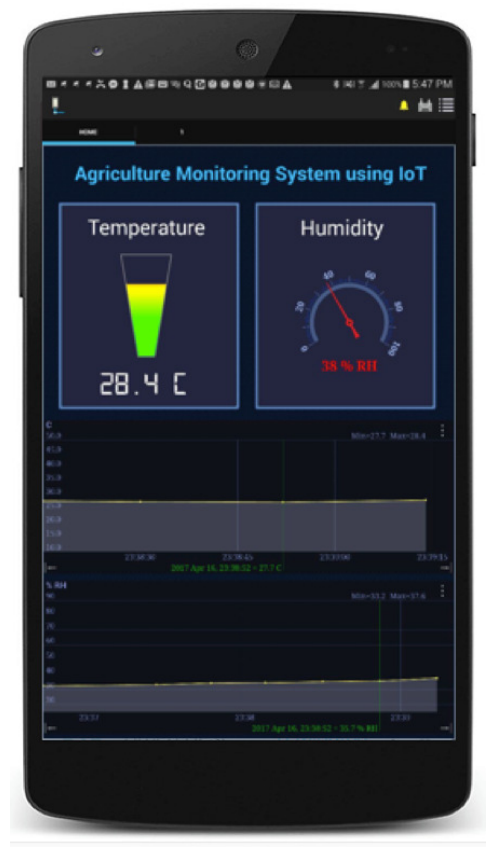

Figure 5. Android app interface

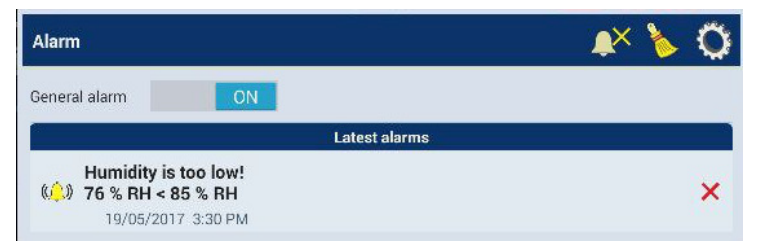

Figure 6. Notification shown when humidity is less than $85 \% \mathrm{RH}$.

\subsection{Performance Testing}

After the interface circuit was built, the results and performance of the system was systematically recorded in a spreadsheet. Sensor values acquired were validated first by comparing it to a reliable source or device. Then, behavior of the monitoring and control system was examined by placing the system in an actual mushroom farm.

The control devices in the mushroom farm should be controlled automatically to maintain the environment in a specific range. The range depends on the mode (spawn-run, pinhead initiation, cropping) selected. The performance index is measured at the completion of the system by taking the recording and analyzing the data from sensor after the system was turned on.

\section{RESUlts AND DISCUSSION}

The developed interface circuit was able to measure temperature, humidity, light intensity and carbon dioxide concentration, and was able to control LED, fan and humidifier based on the data measured. Figure 7 shows the developed interface circuit. 


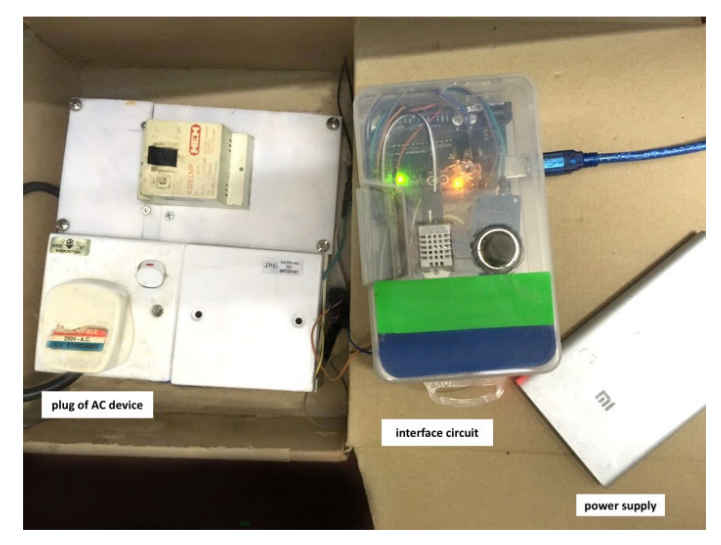

Figure 7. Interface circuit

Performance test was done for each sensor after the interface circuit was developed. The results were recorded and compared with a commercial device in Table 2 to 5 .

Table 2 and 3 shows the comparison of temperature and humidity measured using the interface circuit developed and HTC-1 digital temperature and humidity meter. Using HTC-1 meter as reference, the average error of temperature measure by the interface circuit was $\pm 0.3^{\circ} \mathrm{C}$. The maximum percentage error is $2.2 \%$, while the minimum percentage error of temperature is $0.4 \%$. The average error of humidity measured was $\pm 1.8 \% \mathrm{RH}$. The minimum percentage error of humidity is $1.5 \%$.

The measured light intensity using the interface circuit was compared with the data measured by using TASI-8720 lux meter. From Table 4, the minimum percentage error of the light sensor is $3.5 \%$, while the maximum percentage error is $14.3 \%$.

The carbon dioxide sensor MQ135 was placed outdoor to measure carbon dioxide level and the value measured was compared to the atmospheric carbon dioxide level shown at www.co2.earth. As of April 2017, the atmospheric carbon dioxide level was 409.01ppm. Table 4 shows the carbon dioxide concentration measured using MQ135. Based on Table 5, the minimum percentage error of the carbon dioxide measured is $1.34 \%$, while the maximum percentage error is $4.89 \%$.

Table 2. Comparison of temperature measured using the interface circuit and HTC-1 meter.

\begin{tabular}{|c|c|c|c|c|}
\hline Time & $\begin{array}{c}\text { Data from interface } \\
\text { circuit } \\
\left({ }^{\circ} \mathbf{C}\right)\end{array}$ & $\begin{array}{c}\text { Data from HTC-1 } \\
\left({ }^{\circ} \mathbf{C}\right)\end{array}$ & $\begin{array}{c}\text { Error } \\
\left({ }^{\circ} \mathbf{C}\right)\end{array}$ & $\begin{array}{c}\text { Percentage } \\
\text { Error }(\boldsymbol{\%})\end{array}$ \\
\hline $9: 00$ & 26.2 & 26.6 & 0.4 & 1.5 \\
\hline $9: 05$ & 26.2 & 26.8 & 0.6 & 2.2 \\
\hline $9: 10$ & 26.1 & 26.5 & 0.4 & 1.5 \\
\hline $9: 15$ & 26.5 & 26.7 & 0.2 & 0.7 \\
\hline $9: 20$ & 26.5 & 26.6 & 0.1 & 0.4 \\
\hline $9: 25$ & 26.5 & 26.6 & 0.1 & 0.4 \\
\hline $9: 30$ & 26.5 & 26.7 & 0.2 & 0.7 \\
\hline
\end{tabular}

Table 3. Comparison of humidity measured using the interface circuit and HTC-1 meter. 
International Journal of Computer Science \& Information Technology (IJCSIT) Vol 9, No 4, August 2017

\begin{tabular}{|c|c|c|c|c|}
\hline Time & $\begin{array}{c}\text { Data from interface } \\
\text { circuit } \\
(\boldsymbol{\%} \mathbf{R H})\end{array}$ & $\begin{array}{c}\text { Data from HTC-1 } \\
(\boldsymbol{\%} \mathbf{R H})\end{array}$ & $\begin{array}{c}\text { Error } \\
(\boldsymbol{\%} \mathbf{R H})\end{array}$ & $\begin{array}{c}\text { Percentage } \\
\text { Error }(\boldsymbol{\%})\end{array}$ \\
\hline $9: 00$ & 62.1 & 60 & 2.1 & 3.5 \\
\hline $9: 05$ & 64.7 & 63 & 1.7 & 2.7 \\
\hline $9: 10$ & 71.5 & 70 & 1.5 & 2.1 \\
\hline $9: 15$ & 69.4 & 67 & 2.4 & 3.6 \\
\hline $9: 20$ & 66 & 65 & 1 & 1.5 \\
\hline $9: 25$ & 65.9 & 64 & 1.9 & 3 \\
\hline $9: 30$ & 64.2 & 62 & 2.2 & 3.5 \\
\hline
\end{tabular}

Table 4. Comparison of light intensity measured using the interface circuit and TASI-8720 lux

\begin{tabular}{|c|c|c|c|c|}
\hline Condition & $\begin{array}{c}\text { Data from } \\
\text { interface circuit } \\
\text { (lux) }\end{array}$ & $\begin{array}{c}\text { Data from TASI- } \\
\mathbf{8 7 2 0} \text { (lux) }\end{array}$ & $\begin{array}{c}\text { Error } \\
\text { (lux) }\end{array}$ & $\begin{array}{c}\text { Percentage } \\
\text { Error (\%) }\end{array}$ \\
\hline $\begin{array}{c}\text { Indoor with lights } \\
\text { on (day time) }\end{array}$ & 311 & 324 & 13 & 4 \\
\hline $\begin{array}{c}\text { Indoor without } \\
\text { lights (day time) }\end{array}$ & 30 & 35 & 5 & 14.3 \\
\hline $\begin{array}{c}\text { Outdoor (day } \\
\text { time) }\end{array}$ & 12229 & 12400 & 441 & 3.5 \\
\hline Outdoor (7pm) & 690 & 740 & 50 & 6.8 \\
\hline
\end{tabular}

Table 5. Comparison of $\mathrm{CO} 2$ concentration measured using the interface circuit and atmospheric $\mathrm{CO} 2$ concentration.

\begin{tabular}{|c|c|c|c|}
\hline Date & $\begin{array}{c}\text { Data from interface } \\
\text { circuit (ppm) }\end{array}$ & Error (ppm) & $\begin{array}{c}\text { Percentage Error } \\
(\mathbf{\%})\end{array}$ \\
\hline 26-Apr-17 & 392.4 & 16.61 & 4.06 \\
\hline $27-A p r-17$ & 414.5 & 5.49 & 1.34 \\
\hline $28-A p r-17$ & 389 & 20.01 & 4.89 \\
\hline 29-Apr-17 & 415.2 & 6.19 & 1.51 \\
\hline 30-Apr-17 & 398.1 & 10.91 & 2.67 \\
\hline
\end{tabular}

Two on-site performance tests were carried out in a mushroom farm at Batu Lancang, Penang. The first test was carried out on 8 May 2017 and the second test was carried out on 9 May 2017. In both performance tests, temperature, humidity, light intensity and carbon dioxide concentration were measured by the system and sent to ThingSpeak server every 10 minutes.

During the first test, a timer was used to control an ac powered humidifier. Results of the first test shows that temperature, humidity and light intensity in the mushroom farm on 8 May 2017 did 
not reach the optimum condition. The average temperature, humidity and light intensity measured on the day were 27.6 degrees Celsius, $75.4 \% \mathrm{RH}$, and 90.36lux respectively, while the optimum condition is temperature below 25 degrees Celsius, humidity above $85 \% \mathrm{RH}$ and light intensity above 500lux.

During the second test, the humidifier in the farm was connected to the relay in the interface circuit designed, instead of the timer. "Cropping" mode was selected as to maintain humidity at $85 \% \mathrm{RH}$ or above and temperature at 25 degrees Celsius or below by controlling the existing humidifier, fluorescent light and fan in the mushroom farm.

In the second test where the sensor-based control system was used, the environmental condition of the mushroom farm was much nearer to the optimum condition. Average temperature in the second test was 26.4 degrees Celsius and minimum temperature achieved was 25.7 degrees Celsius. Humidity, carbon dioxide concentration and light intensity were successfully maintained in the range of optimum condition throughout the second test. The result recorded during both tests is as shown in Figure 8. The data labelled as "uncontrolled" is the data recorded in the first test while the data labelled as "controlled" is the data recorded in the second test.

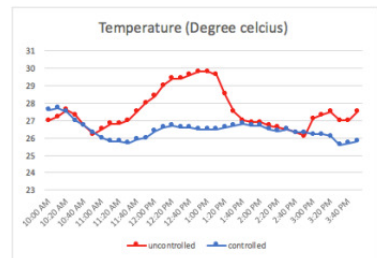

(a)

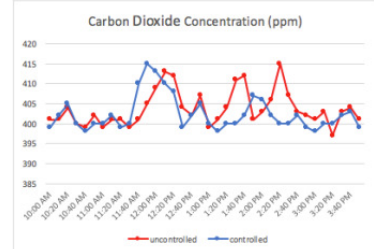

(c)

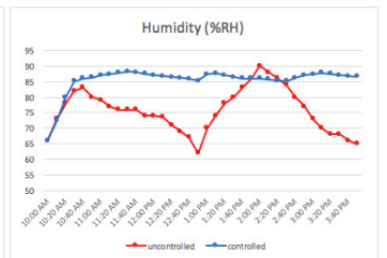

(b)

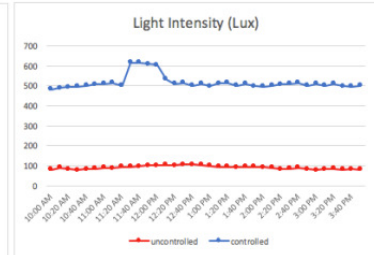

(d)

Figure 8. Graph of (a) Temperature (b) Humidity (c) Carbon Dioxide Concentration (d) Light Intensity recorded in Batu Lancang mushroom farm during the first and second tests.

\section{Conclusions}

The interface circuit for agriculture sensors was developed successfully. The circuit includes a monitoring function, which enables user to monitor temperature, humidity, carbon dioxide concentration and light intensity in a mushroom farm wirelessly, and a control function, which is able to control the condition in the mushroom farm, based on the feedback of the sensors.

The measured percentage error of temperature, humidity, carbon dioxide and the light intensity using the circuit was as low as $0.4 \%, 1.5 \%, 2.2 \%$ and $1.34 \%$ respectively.

The monitoring system was able to acquire sensor data and send the data to ThingSpeak online cloud for monitoring and storage. The data could be accessed by the user anytime by using a computer that is connected to the Internet. It could also be downloaded into .CSV file for further analysis. An Android app interface was also designed to ease data monitoring.

The control system was able to control ac-powered humidifier, light and fan based on the feedback of the sensors to maintain temperature, humidity, carbon dioxide concentration and light intensity at optimum growth condition in an actual mushroom farm. 
International Journal of Computer Science \& Information Technology (IJCSIT) Vol 9, No 4, August 2017

\section{ACKNOWLEDGEMENTS}

This research work had been supported the Ministry of High Education Malaysia (MOHE)/Universiti Sains Malaysia (USM) under the project/grant number FRGS:203/PELECT/6071348.

\section{REFERENCES}

[1] Unit Pengurusan Prestasi dan Pelaksanaan (2010) Economic Transformation Programme: A Roadmap for Malaysia (1 Malaysia). Performance Management and Delivery Unit, Jabatan Perdana Menteri.

[2] Istikoma Qurat-ul-Ain., \& Dahlan A. R. A, (2015) "The Transformation of Agriculture Based Economy to an Industrial Sector through Crowd Sourcing In Malaysia”, Int. J. Comput. Sci. Inf. Technol. Res., Vol. 3, No. 1, pp.34-41.

[3] Bakar B.B., (2009) "The Malaysian Agricultural Industry in the New Millennium - Issues and Challenges," pp. 337-356.

[4] Rosmiza M., Davies W., Aznie R. C., Jabil M., \& Mazdi M, (2016) "Prospects for Increasing Commercial Mushroom Production in Malaysia: Challenges and Opportunities", Mediterr. J. Soc. Sci., Vol. 7, No. 1, pp. 406-415.

[5] Haimid M. T., Rahim H., \& Dardak R. A, (2013) "Understanding the mushroom industry and its marketing strategies for fresh produce in Malaysia”, Econ. Technol. Manag. Rev., Vol. 8, pp. 2737.

[6] Mat Amin M. Z., \& Harun A, (2015) "Competitiveness of the Mushroom Industry in Malaysia" [Online]. Available: http://ap.fftc.agnet.org/ap_db.php?id=481\&print=1. [Accessed: 18-Oct-2016].

[7] Australian Mushroom Growers Association, "Introduction to Mushroom Growing," AMGA, pp. 116.

[8] Van Nieuwenhuijzen, Bram., \& Oei, P (2005) Small-scale mushroom cultivation oyster, shiitake and wood ear mushrooms, Agrodok;40. Agromisa/CTA, Wageningen, The Netherlands.

[9] Stamets P., \& Chilton, J. S, (1983) "The Mushroom Cultivator: A Practical Guide to Growing Mushrooms at Home", S. Cal. L. Rev., p. 416.

[10] Grant, J.J (2002) An investigation of the airflow in mushroom growing structures, the development of an improved, three-dimensional solution technique for fluid flow and its evaluation for the modelling of mushroom growing structures. $\mathrm{PhD}$ thesis, Dublin City University.

[11] Kwon H., \& Kim, B. S (2004) Mushroom Grow. Handb. 1, pp. 192-196.

[12] Tisdale T. E (2004) Cultivation of the Oyster Mushroom (Pleurotussp.) on Wood Substrates in Hawaii. MSc thesis, University of Hawai'i.

[13] Wang X., (2014) "Temperature and Humidity Monitoring System Based on GSM Module", International Journal of Computer, Consumer and Control., Vol. 3, No. 1, pp. 41-49.

[14] Rahali A., Guerbaoui M., Ed-dahhak A., El Afou Y., Tannouche A., Lachhab A., \& Bouchikhi, B, (2011) "Development of a data acquisition and greenhouse control system based on GSM", Int. J. Eng. Sci. Technol., Vol. 3, No. 8, pp. 297-306.

[15] Kalinin Y. S., Velikov E. K., \& Markova, V. I, (2015) "Design of Indoor Environment Monitoring System Using Arduino”, Int. J. Innov. Sci. Mod. Eng., Vol. 3, No. 7, pp. 46-49, 20.

[16] Lokesh Krishna K., Madhuri J., \& Anuradha K, (2016) “A ZigBee based Energy Efficient Environmental Monitoring Alerting and Controlling System", in International Conference On Information Communication And Embedded Systems (ICICES2016). 
International Journal of Computer Science \& Information Technology (IJCSIT) Vol 9, No 4, August 2017

\section{Authors}

Arjuna Marzuki is a lecturer at Universiti Sains Malaysia. He teaches Analog Circuit design at School of Electrical and Electronic Engineering

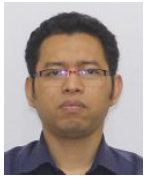

Yan Ying Soh is a student of electronic engineering at School of Electrical and Electronic Engineering 